\title{
When Leadership Fails - A View From The Lens Of Four Employees
}

Laurie L. Barnes, Liberty University, USA

Janice M. Spangenburg, Liberty University, USA

\begin{abstract}
Leadership is a concept that has been used for decades and despite what we know about it there are many things left to the unknown. We must keep moving forward to search for answers as we seek to explain the many failures that exist today. For centuries, reports of lackluster and even abusive leadership in organizations have continued to be a negative force in organizations, adversely impacting culture and overall performance. Amid the challenges facing leaders as well as the necessity for rapid and continuous change in the organization, we see the development of many problems and consequent ails that need to be addressed. We are often left with supervisors that abuse without regard for the breakdown of loyalty, job satisfaction and the development of a solid and rich culture that can support thriving and positive organizational outcomes. This has been captured in the voices and experiences of individuals interviewed for this qualitative case study analysis, demonstrating the continued impact of leadership in modern day organizations and well as addressing the perplexing question of how to distinguish who would or would not be a best fit for leadership positions in today's organizations. Despite years of research, theory and analysis, perhaps the greatest insight is gained through the lens of the employee.
\end{abstract}

Keywords: Organizational Conflict; Leadership Styles; Leadership Behavior; Abusive Leadership; Abusive Supervision

\section{OVERVIEW}

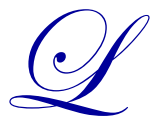
eadership has been the foundation for many concepts, both positive and negative, that have surfaced in organizations. People are sometimes the target of poor leadership in organizations and become impacted with these underpinnings of such dark, lackluster or self-centered leadership. Leadership comes in both bad and good and we must understand the distinctions between the good and bad in an effort to develop our overall understanding. One of these characterized bad developments can emerge as abusive leadership. Nearly every employee has a supervisor or manager of some form and some find supervisors not emulating the best characteristics. Negative connotations, attitudes and perceptions can thereby ensue. Researchers have spent decades in the quest to understand more about the organization and the best ways in which leadership can make a difference, so there must be more than theory and analysis has provided thus far.

People need to work, but how can they work and maintain their esprit de corps and team spirit and accomplish the mission and vision when we are faced with the negative situations of the modern workplace? Work is often challenging enough without having to come into a workplace that is less than desirable and deal with the conflict between employees let alone the stress of a manager who cannot seem to effectively lead the team in the right direction. This upsets the general culture and is a very undesirable element of the organizational day. If employees held any motivation or commitment to the organization, this can completely demolish it. They often must be actors as a result and press on to get it all done remembering the responsibility and accountability elements of the job and life responsibilities. Leaders and managers need to gain greater insight into the meaning of effective leadership in absence of self-serving interests or negatively projecting frustrations onto employees. Such behavior leads to the general perceptions of abuse and negativity, which inevitably impacts the overall organization. 


\section{REVIEW OF LITERATURE}

In order to understand the impact of abusive supervision, there must be a cursory review of the literature. Tepper (2000) defined abusive supervision as subordinates' perceptions of the extent to which supervisors engage in the sustained display of hostile verbal and non-verbal behaviors, excluding physical contact. This is subjective in nature, but it is something that many of us have faced at some point in the workplace. Behaviors can vary depending on the situation or the individual perception.

A great deal of literature has been written on this topic and topics that intersect and impact abusive supervision. When researchers conduct studies in these areas, the justice literature is most often cited and the issue of fairness seems to be the root of the problem. Employees would certainly be at the forefront to speak to this directly from experience. In every organizational situation there is the element of fairness and justice that goes on daily. In fact, fairness concerns become more salient to employees when they experience uncertainty (Thau, Bennett, Mitchell, \& Marrs, 2008. Abusive supervision has been chronicled and even practiced for a long time but it has more recently been evidenced and surfaced in organizations. There is no one answer why this has occurred and we may not know the answer but it could be the daily routines of leaders that leave them stressed and frustrated where they target the employees or take it out on them. While this is wrong and very unnecessary, it also causes undue grief. This grief is immeasurable and can create substantial organizational ails to include a loss in respect of leadership and a lack of commitment to the overall organization as productivity and effort wanes. It is something that can turn the workplace upside down. Tepper (2000) offered that his study drawing on justice theory examined the consequences of abusive supervisor behavior. The more abusive the behavior perceived the greater chance the subordinate would leave. However, for those who decided to remain, the enduring abusiveness resulted in lower commitment, conflict between work and family, and psychological stress among other outcomes as well as those mentioned do occur and can be a frequent event. Even today, employees will put up with this abuse to meet obligations which seems to contradict what the textbooks say about the way organizations should operate.

There is no need to have several characters or actors in a situation because in a communication situation there may only be two individuals with a number present or observing. However, in abusive supervision situations, the employee or employees and the supervisor are the key players. As a result, the whole aura of abusive supervision brings in the dyadic illustration between two or more individuals and begs the engagement of these parties in the scenario. Additionally, the relationships with supervisors are the most vital above any other in the workplace (Tepper, Carr, Breaux, Geider, Hu, \& Hua, 2009). This was learned earlier in the 1920s with the Hawthorne studies where a lightening experiment demonstrated the level of lighting was not as impacting as the relationships with the supervisors (cite for Hawthorne Studies) Poon went further to bring forth a study that captured some of these aspects. In fact, Poon (2011) conducted an interesting study involving diverse populations in Malaysia. It was found that abusive supervision related negatively and coworker support related positively with work engagement but did not interact to predict work engagement results. Thus, there was no support for a buffering effect (p. 65). This speaks to the thought that despite enduring the abuse the coworker support is the solid factor and serves to "divide the waters". Without this support, the abusive supervision would have a totally negative outcome and a different response, altogether. The absence of a buffering affect ripples through the organization and the signals it produces are equally negative. This effect is the perfect backdrop for abuse and abusive supervision.

Abusive supervision can rise up at any time to varying degrees and without warning. As a result, many cases of abusive supervision are more subtle than others; they still seem to leave us with deep and lasting pain. This can have both a positive and negative effect. However, if this pain suffered has enabled a lesson to be learned, we are much better for it in the long run. In the short run that is not the case. However, there can be instances where there is a mixture of outcomes from abusive supervision. It does depend on the individual where everyone is not tolerant of the same events over time. When one is a member of the organization, it is very important to have that belongingness nature that emerged in the Maslow Hierarchy of Needs (Maslow, 1954) as it related to human needs. It is thought that being a part of the bigger whole helps get the job function accomplished and the objectives realized. Similarly, the views of some leaders this is that no responses from the employees in the lack of effort or any negatives that would detract from accomplishing the mission is not sanctioned. As a result, employees often just keep going because the consequences of not working can outweigh the emotional cost in the moment. This would seem that the supervisor then escapes any attention or consequences with acting inappropriately, but this is not 
necessarily best for employees or the organization as a whole. These seemingly basic interactions can have a ripple effect and may even represent a trend across the organization.

\section{METHOD}

The purpose of this research journey was to uncover some of the examples of abusive leadership in today's organizations, revealing the actual scenarios while also gaining greater insight into the employee perspective of how things might improve. This qualitative research process began with an inquiry sent via email to the employees within three small organizations across three different industries. No employees were in any type of leadership role within their respective companies. There was a total of 156 employees emailed with 84 responses with the understanding that all responses would remain anonymous. There were only 10 that responded with a yes to our question regarding abusive supervision. An interview was done using email and survey monkey to capture the qualitative information for analysis and comparison. There were 4 individuals interviewed as a part of this study and we safeguarded the data to protect the study participants with disclosure, explaining that this was all voluntary and would remain fully anonymous. We used open ended surveys with 5 questions. The intent of the open ended nature gave the respondents a voice where they could freely share as much or as little as they wanted. Answers to these questions were transposed into a scenario description for each respondent. These questions posed were as follows:

1. Describe the scenario in which you perceived that you were the victim of abusive leadership, including the actions of the leader.

2. Did this change your perception of your leader and/or the organization? Explain.

3. How did you respond to this situation?

4. Have things improved since this scenario? Explain.

5. From your perspective, what changes in leader behavior would have been most helpful?

\section{RESULTS}

The information retrieved from the four respondents' answers has been summarized in paragraph format for consideration in each of these scenarios. These are written in third person with no reference to any identifying information for any of the participating parties to fully protect the employees as well as the organizations. These respondents answered all or most of the questions posed with varying detail as outlined below.

Respondent 1 reported: An example of one such incident in leadership breakdown and abusive supervision was a manager that withheld information from an employee. Such an example occurred in a very complex organization where the individual was not invited to the departmental meetings about important subject matter and was not given information about the direction or future of this department. The information about the time and place of such meetings came in the form of the rumor mill in the organization. This employee showed up for every meeting and was apprised of what was going on in the department. The manager did not like this and felt that this employee was being insubordinate because there was no invitation to attend the meetings. This employee did not let this affect anything relating to attitude, focus or doing a quality job every day. No manager should ignore an employee or keep someone from knowing what is going on since information is vital to understanding and accomplishing the job. The manager sought to make this employee "pay" for these actions but it was only right for this person to attend these meetings. This situation created a major base of conflict between the employee and the supervisor, which was left unresolved.

Respondent 2 said: An example arose when a town hall meeting was set up with top leadership coming to town to discuss the future downsizing that would impact the individual's organization. The people needed to be at this meeting to know what was coming down the line and when the meeting was revealed and set up all but one of the organizations knew to come to the meeting at the appointed place and time. This was terribly wrong and could have been a real devastation to these individuals who would ultimately be the victims of the downsizing, leaving a perception that they were purposefully left out of the discussions. The information was transcended again through company gossip and not of the official kind, so members did attend the meeting to the leaders and manager's dismay. Ignoring employees is a tragedy that results in a negative slant on those in leadership roles. This led to a lack of trust for company leadership and this is something that has not been regained. 
Respondent 3 said: A third example shared was the one of a supervisor that seemed to desire positional power over consideration for true leadership. This was captured by two scenarios addressed in one response on this interview. When the leader asked the employee to work on projects on two different occasions, hours and days were spent with research and preparation. In presenting the information to the Director, all of the work was shredded tin front of the employee with a simple statement that "this is garbage". This incident led to complete frustration and distrust for the leader. The employee admittedly no longer holds the same regard or loyalty to the organization since this occurred. In this situation, the employee was a long-time employee and the supervisor had been there a few months.

Respondent 4 shared that: One great example of distrust and disrespect is the kind of action by a supervisor to intimidate and chip away at an employee's self-esteem. With this employee sitting just outside of the office of the supervisor, the supervisor was watching and listening in on all the employee was doing. In steps that seemed to go beyond micro-management, the supervisor requested that employees not change phone passwords so the supervisor could listen to messages for anyone at any time. The supervisor yells at this particular employee in front of the entire department, leaving the individual to feel abused and "beaten down". This unfortunate scenario has led the employee to feel disdain for the supervisor and the individual is actively seeking another position.

\section{CONCLUSION}

As many examples and scenarios have been addressed through this brief qualitative research study, it is also important to remember those scenarios that may be a little less obvious yet just as impacting. As we reflect on this great paradox of leadership, we are reminded of those leaders that present themselves as interested in the greater good while their actions are tearing down the morale and culture of the organization. This is something that tends to be more subtle over time, but employees can sense this as their motivation and drive begins to wane and they begin to question how things ended up this way. Behind the scenes, leaders are making poor decisions and changes that impact the roles and tasks of the employees, sometimes pushing them beyond their expertise or abilities or even devaluing their input and purpose. Essentially, they are setting people up to fail and them faulting them for such failures. This is something that can be observed as employee turnover rates increase, organizational commitment decreases, motivation and production fall and there is no sense of extra-role behavior among employees (Emery \& Barker, 2007). A negative shift in culture can be detrimental to the entire organization and it can take considerable time to repair.

Abusive supervision is still very much alive and kicking in organizations of every size and industry around the world. It is a wicked sting of the bee when we are faced with this and we really need to keep educating ourselves and doing more to combat this harmful outcome. Sosik (2005) asserts that employees strive for empowerment and meaning within the workplace, which leads to greater enthusiasm and motivation in performing their jobs. We cannot permit abusive leadership to affect and impact our morale, motivation and ability to do a quality job every day. We need to act now and act together to beat this bee and turn the stinger around on time. Maybe feeling the sting themselves, would take the supervisor and these who are notorious for this kind of action into a new realm. Albeit, this is leadership less than authentic and pseudo-transformational in context and can have a truly lasting negative outcome (Thau et al. 2008). We have to stamp this out and keep this from souring and tainting our experience. We cannot let this tear down our character or impact or esteem (Spangenburg, 2012). We must remember that with a more educated workforce that one day some of this learning about what is supposed to be in the organizations will take effect and reduce or at least mitigate abusive supervision as we know it. At least it is hoped that through education and knowledge we can change the world through people and organizations, despite the size, one at a time.

Research shows that part of what forms our opinion of leaders is ethics, character and authenticity (Bass \& Steidlemeir, 1999). The perception of ethics, character and authenticity goes with it. Scenarios such as those described in this study can destroy any respect for the leader and trust can be irreversibly broken. This study reiterates the point that there is still much to be learned about leadership and there are many that could benefit from growth and development in this area. Abusive leadership is unacceptable and should not exist within our vibrant and dynamic organizations today. With the level of research and understanding that exists on the importance of the role of the leader, continued and more extensive research is still necessary for defining the distinctions between those that should and should not be chosen to lead our organizations into the future. Through this brief case study, 
there is a reminder that abusive leadership continues to exist and one of the greatest sources for insight and scholarship rests within the perceptions, interpretations and suggestions of these frontline employees.

\section{AUTHOR BIOGRAPHIES}

Dr. Barnes worked for over 13 years working for the Commonwealth of Virginia and has managed in two consulting practices as well as a small retail business venture. During this time, Dr. Barnes served in various management and leadership roles. Additionally, Dr Barnes has worked in academia for over 13 years, teaching undergraduate and graduate level courses in Business, Management, Leadership and Psychology, serving in a mentor capacity through the years at various academic institutions. She has helped to train and advise management in for-profit and non-profit organizations through consulting, focusing on business strategy, change leadership, and organizational diagnosis. E-mail: laurie91@msn.com

Dr. Spangenburg spent over 24 years in the military and federal government working with all five services. Dr. Spangenburg has led two successful management consulting practices and has served on the Board of Directors for a Credit Union and is currently on the Board of Directors for the Association of Accredited Small Business Consultants, mentors, and she advises government and organizations on business and leadership matters. Dr. Spangenburg has held various positions in higher education, both administrative and teaching, for over 18 years; has been very involved with both graduate and undergraduate courses, including teaching and mentoring; and has led the way for transformative and innovative educational products for academic institutions in degree programs on every academic level. E-mail: drjanices@msn.com

\section{REFERENCES}

Bass, B. M., \& Steidlmeier, P. (1999). Ethics, character, and authentic transformational leadership behavior. The Leadership Quarterly, 10(2), 181-217

Beye, C. (1976). The Iliad and the Odyssey-and the epic tradition. New York: Gordian Press.

Emery, C. R. \& Barker, K. J. (2007). The effect of transactional and transformational leadership styles on the organizational commitment and job satisfaction of customer contact personnel. Journal of Organizational Culture, Communication and Conflict, 11(1), 77-90.

Maslow, A (1954). Motivation and personality. New York, NY: Harper.

Poon, J. (2011). Effects of abusive supervision and coworker support on worker engagement. $20112^{\text {nd }}$ International Conference on Economics, Business and Management, IPEDR Vol. 22 (2011) IACSIT Press, Singapore

Sosik, J. J. (2005). The role of personal values in the charismatic leadership of corporate managers: Content and contextual comparisons. Journal of Leadership \& Organizational Studies, 10(4), 80-92.

Spangenburg, J. (2012), The effect of a pseudo transformational leader: Whitewater rafting in a hurricane. International Journal of Management and Information Systems, 16(4). Available: www.cluteinstitute.com

Tepper, B. (2000). Consequences of abusive supervision. Academy of Management Journal, 43(2), 178-190.

Tepper, B., Carr, J., Breaux, D., Geider, S., Hu, C. \& Hua, W. (2009). Abusive supervision, intentions to quit, and employee's workplace deviance: A power/dependence/analysis. Organizational Behavior and Human Decision Processes. Available: www.elesvier.com/locate.obhdp

Thau, S., Bennett, R, Mitchell, M. \& Marrs, M. (2008). How management style moderates the relationship between abusive supervision and workplace deviance: An uncertainty management theory perspective. University of Nebraska-Lincoln. Digital commons@University of Nebraska-Lincoln. 
NOTES 